PAPER

\title{
Impact of pyrexia on neurochemistry and cerebral oxygenation after acute brain injury
}

\author{
N Stocchetti, A Protti, M Lattuada, S Magnoni, L Longhi, L Ghisoni, M Egidi, E R Zanier
}

J Neurol Neurosurg Psychiatry 2005;76:1135-1139. doi: 10.1136/jnnp.2004.041269

See end of article for authors' affiliations

........

Correspondence to: Professor Nino Stocchetti, Terapia Intensiva

Neuroscienze, Ospedale

Policlinico IRCCS Milano, Padiglione Beretta Neuro Via F Sforza 35, 20122

Milan, Italy; stocchet@

policlinico.mi.it

Received 11 March 2004

In revised form

5 October 2004

Accepted

3 November 2004

\begin{abstract}
Background: Postischaemic pyrexia exacerbates neuronal damage. Hyperthermia related cerebral changes have still not been well investigated in humans.

Objective: To study how pyrexia affects neurochemistry and cerebral oxygenation after acute brain injury. Methods: 18 acutely brain injured patients were studied at the onset and resolution of febrile episodes (brain temperature $\geqslant 38.7^{\circ} \mathrm{C}$ ). Intracranial pressure $(I C P)$, brain tissue oxygen tension $\left(\mathrm{P}_{\mathrm{br}} \mathrm{O}_{2}\right)$, and brain tissue temperature $\left(\mathrm{T}_{\mathrm{br}}\right)$ were recorded continuously; jugular venous blood was sampled intermittently. Microdialysis probes were inserted in the cerebral cortex and in subcutaneous tissue. Glucose, lactate, pyruvate, and glutamate were measured hourly. The lactate to pyruvate ratio was calculated.

Results: Mean (SD) $\mathrm{T}_{\mathrm{br}}$ rose from $38(0.5)$ to $39.3(0.3)^{\circ} \mathrm{C}$. Arteriojugular oxygen content difference $\left(\mathrm{AJDO}_{2}\right)$ fell from $4.2(0.7)$ to $3.8(0.5)$ vol\% $(\mathrm{p}<0.05)$ and $\mathrm{P}_{\mathrm{br}} \mathrm{O}_{2}$ rose from $32(21)$ to $37(22) \mathrm{mm} \mathrm{Hg}$ $(p<0.05)$. ICP increased slightly and no significant neurochemical alterations occurred. Opposite changes were recorded when brain temperature returned towards baseline.

Conclusions: As long as substrate and oxygen delivery remain adequate, hyperthermia on its own does not seem to induce any further significant neurochemical alterations. Changes in cerebral blood volume may, however, affect intracranial pressure.
\end{abstract}

$\mathrm{T}$ he initial cerebral damage after acute brain injury is often exacerbated by superimposed insults. ${ }^{1}$ Fever is a common problem during neurosurgical intensive care; in retrospective studies, the proportion of febrile patients ranged from $47 \%^{2}$ to $85 \%,{ }^{1}$ depending on inclusion criteria. Postischaemic hyperthermia amplifies the brain damage and worsens the outcome. ${ }^{3}$ It triggers the release of excitatory amino acids and free radicals, aggravates blood-brain barrier breakdown, exacerbates cytoskeletal proteolysis, and increases cerebral metabolic rate. ${ }^{4-6}$

New monitoring techniques can now promptly detect adverse events in specific areas of the brain cortex. Microdialysis measures the chemical composition of the extracellular fluid. ${ }^{7}$ Minimally invasive probes continuously record partial pressure of oxygen, carbon dioxide, $\mathrm{pH}$, and temperature in the surrounding tissue. ${ }^{89}$

Hyperthermia related cerebral changes have still not been well explored in humans. Most data come from animal models of cerebral ischaemia ${ }^{4}$ or from hypothermia studies. ${ }^{10-12}$ Our aim in this study was to describe the impact of pyrexia on neurochemistry and cerebral oxygenation after an acute brain injury.

\section{METHODS}

Patients

We studied patients admitted to the intensive care unit (ICU) because of subarachnoid haemorrhage or head injury, after obtaining written consent from the next of kin. The study was approved by the hospital ethics committee. The motor component of the Glasgow coma scale (GCS) was assessed on admission and when intracerebral catheters were positioned. Six months after injury, outcome was evaluated using the Glasgow outcome scale (GOS).

\section{Intracranial probes}

A cerebral microdialysis catheter (CMA 70, CMA/ Microdialysis $\mathrm{AB}$, Stockholm, Sweden) with a membrane length of $10 \mathrm{~mm}$ and a permeability cut off of 20000 Daltons was positioned in the brain cortex (usually in normal appearing tissue, as most of the cerebral lesions were diffuse). A subcutaneous catheter (CMA 60) was inserted in the periumbilical adipose tissue. A sterile solution similar to the extracellular fluid $\left(\mathrm{Na}^{+} 147 \mathrm{mmol} / \mathrm{l}, \mathrm{K}^{+} 4 \mathrm{mmol} / \mathrm{l}, \mathrm{Ca}^{2+}\right.$ $2.3 \mathrm{mmol} / \mathrm{l}, \mathrm{Cl}^{-} 156 \mathrm{mmol} / \mathrm{l}$; $\mathrm{pH}$ 6; osmolarity $290 \mathrm{mOsm} / \mathrm{kg}$ ) was perfused at a rate of $0.3 \mu \mathrm{l} / \mathrm{min}$ by a micropump (CMA 106). Vials collected hourly were processed immediately at the bedside using a microdialysis analyser (CMA 600). Glucose and lactate were always measured. Pyruvate and glutamate were sampled in all but the first patient (owing to the temporary unavailability of the reagents). The lactate to pyruvate ratio was then calculated.

As a reference, we report the suggested normal human intracerebral values (mean (SD)) for glucose (1.7 (0.9) $\mathrm{mmol} / \mathrm{l})$, lactate $(2.9(0.9) \mathrm{mmol} / \mathrm{l})$, pyruvate $(0.166(0.047) \mathrm{mmol} / \mathrm{l})$, glutamate (16 (16) $\mu \mathrm{mol} / \mathrm{l})$, and the lactate to pyruvate ratio (23 (4)) for the present equipment and procedures. ${ }^{13}$

Brain tissue oxygen tension $\left(\mathrm{P}_{\mathrm{br}} \mathrm{O}_{2}\right)$ was measured continuously using either a Licox probe (Microcatheter $\mathrm{PO}_{2}$, Licox GMS mbH, Kiel, Germany) or a Neurotrend probe (Neurotrend cerebral tissue monitoring system; Codman, Bracknell, Berkshire, UK). The latter also measure brain tissue carbon dioxide tension $\left(\mathrm{P}_{\mathrm{br}} \mathrm{CO}_{2}\right), \mathrm{pH}\left(\mathrm{pH}_{\mathrm{br}}\right)$, and temperature $\left(\mathrm{T}_{\mathrm{br}}\right)$. In the two cases where a Licox sensor was used, intracranial temperature was recorded by an intraventricular catheter with a thermistor (110-4HTM; Camino Lab, San Diego, California, USA).

Intracranial pressure (ICP) was measured through an intraventricular, subdural, or intraparenchymal catheter.

\footnotetext{
Abbreviations: $\mathrm{AJDO}_{2}$, arteriojugular oxygen content difference; CMRgluc, cerebral metabolic rate of glucose; $\mathrm{CMRO}_{2}$, cerebral metabolic rate of oxygen; CPP, cerebral perfusion pressure; GCS, Glasgow coma scale; GOS, Glasgow outcome scale; ICP, intracranial pressure; $M A P$, mean arterial pressure; $\mathrm{P}_{\mathrm{br}} \mathrm{O}_{2}$, brain tissue oxygen tension; $\mathrm{SJO}_{2}$, jugular saturation at the superior jugular bulb; $\mathrm{T}_{\mathrm{br}}$, brain temperature
} 
Table 1 Main demographic and clinical data

\begin{tabular}{|c|c|c|c|c|c|c|c|c|c|}
\hline Patient & Diagnosis & Sex & Age (years) & mGCS adm & mGCS posit & Mean ICP & Mean CPP & Mean $\mathrm{AJDO}_{2}$ & GOS \\
\hline 1 & $\mathrm{HI}$ & $M$ & 21 & 5 & 5 & 17 & 59 & 4.6 & 4 \\
\hline 2 & $\mathrm{HI}$ & $M$ & 30 & 3 & 3 & 14 & 72 & 3.6 & 4 \\
\hline 3 & $\mathrm{HI}$ & $M$ & 35 & 3 & 5 & 9 & 67 & 4.8 & 3 \\
\hline 4 & $\mathrm{HI}$ & $\mathrm{F}$ & 22 & 3 & 3 & 19 & 84 & 5.3 & 4 \\
\hline 5 & $\mathrm{HI}$ & $M$ & 37 & 2 & 2 & 12 & 58 & 3.9 & 3 \\
\hline 6 & SAH & $\mathrm{F}$ & 43 & 3 & 3 & 19 & 78 & 4.4 & 3 \\
\hline 7 & SAH & $\mathrm{F}$ & 62 & 3 & 1 & 24 & 81 & 3.0 & 3 \\
\hline 8 & $\mathrm{HI}$ & $M$ & 24 & 3 & 3 & 17 & 79 & 5.0 & 3 \\
\hline 9 & SAH & $\mathrm{F}$ & 36 & 6 & 5 & 13 & 86 & 3.1 & 5 \\
\hline 10 & $\mathrm{HI}$ & $M$ & 16 & 4 & 4 & 18 & 65 & 5.1 & 4 \\
\hline 11 & $\mathrm{HI}$ & $M$ & 18 & 4 & 3 & 13 & 77 & 5.0 & 5 \\
\hline 12 & $\mathrm{HI}$ & $M$ & 46 & 5 & 5 & 21 & 59 & 3.6 & 3 \\
\hline 13 & SAH & $\mathrm{F}$ & 54 & 3 & 3 & 26 & 75 & 3.8 & 3 \\
\hline 14 & $\mathrm{HI}$ & $M$ & 22 & 3 & 3 & 16 & 71 & 4.1 & 5 \\
\hline 15 & SAH & $M$ & 57 & 6 & 3 & 25 & 74 & 3.1 & 1 \\
\hline 16 & $\mathrm{HI}$ & $M$ & 85 & 3 & 1 & 11 & 63 & 3.4 & 1 \\
\hline 17 & SAH & $\mathrm{F}$ & 59 & 5 & 1 & 10 & 80 & $\begin{array}{l}3.4 \\
3.5\end{array}$ & 2 \\
\hline 18 & $\mathrm{HI}$ & $\mathrm{F}$ & 40 & 3 & 3 & 21 & 71 & 4.7 & 4 \\
\hline
\end{tabular}

adm, on admission; $\mathrm{ADO}_{2}$, arteriojugular difference in oxygen content; $\mathrm{CPP}$, cerebral perfusion pressure; $\mathrm{F}$, female; GOS, Glasgow outcome score at six months: $1=$ dead, 2 =vegetative status, $3=$ severe disability, $4=$ moderate disability, $5=$ good recovery; $\mathrm{HI}$, head injury; $\mathrm{M}$, male; mGCS, Glasgow coma scale motor component score; ICP, intracranial pressure; posit, at catheter positioning; SAH, subarachnoid haemorrhage.

\section{Monitoring and data acquisition}

Mean arterial pressure (MAP) was monitored in all patients. Cerebral perfusion pressure (CPP) was calculated as MAP minus ICP. Data were recorded continuously and stored in a computer, using an analogue to digital converter (AD Instruments; Castle Hill, New South Wales, Australia). Jugular saturation at the superior jugular bulb $\left(\mathrm{SJO}_{2}\right)$ was measured intermittently and arteriojugular difference in oxygen content $\left(\mathrm{AJDO}_{2}\right)$ was calculated.

Onset of fever (effervescence) was examined by selecting a phase of hyperthermia $\left(\mathrm{T}_{\mathrm{br}} \geqslant 38.7^{\circ} \mathrm{C}\right)$ following, in a 24 hour period, a phase of normothermia $\left(\mathrm{T}_{\mathrm{br}}\right.$ around $\left.38^{\circ} \mathrm{C}\right)$, each lasting two to five hours. Resolution of pyrexia (defervescence) was studied by searching the individual brain temperature recordings for a phase of normothermia following any phase of pyrexia (both lasting two to five hours) within 24 hours. In patients experiencing more than one episode of effervescence or defervescence, the one reaching the highest brain temperature at the febrile peak was selected. Care was taken to select episodes during which there was no active intervention, such as administration of mannitol, changes in ventilator settings, or withdrawal of cerebrospinal fluid. For each phase, the mean metabolite concentrations were calculated and the corresponding ICP, $\mathrm{CPP}, \mathrm{SJO}_{2}, \mathrm{AJDO}_{2}, \mathrm{P}_{\mathrm{br}_{2}}, \mathrm{P}_{\mathrm{br}_{2}} \mathrm{CO}_{2}, \mathrm{pH}_{\mathrm{br}}$, and $\mathrm{T}_{\mathrm{br}}$ recordings were averaged.

\section{Statistical analysis}

All data are summarised as mean (SD). Episodes of effervescence and defervescence are considered as two independent groups, as some of the patients experienced only one of the two phases. The paired $t$ test was used to compare differences between data collected during normothermia and at the febrile peak. A probability ( $p$ ) value of $<0.05$ was accepted as significant.

\section{RESULTS}

We studied 18 patients ( 11 male, 7 female) suffering from traumatic brain injury $(n=12)$ or aneurysmal subarachnoid haemorrhage $(n=6)$. Their mean age was 39 years (range 16 to 85 ). The median score of the motor component of the GCS was 3 on admission (range 2 to 6) and when intracranial catheters were positioned (range 1 to 5 ). Table 1 shows the main data on the neurological presentation and clinical course.
There were no complications from the intracranial catheters. Mean (SD) time of data collection was 101 (37) hours.

Fever was frequent during intensive care, despite antibiotic and antipyretic treatment. On average, it was observed for 37 (27)\% of the total monitoring time. Thirteen episodes of effervescence were analysed (in five patients no stable phase of normothermia preceding pyrexia was identifiable). An episode of defervescence was detected in 14 patients. The mean (SD) length of each phase was 3 (1) hours, and 142 hours were analysed. In all, 1084 cerebral and subcutaneous samples were examined. $\mathrm{P}_{\mathrm{br}} \mathrm{O}_{2}$ monitoring was considered reliable in only 14 patients because of probe malfunction.

Data collected during the selected episodes of onset and resolution of pyrexia are shown in tables 2 and 3.

\section{Cerebral variables and neurochemistry during effervescence}

On average, intracranial temperature rose from $38(0.5)$ to $39.3(0.3){ }^{\circ} \mathrm{C}$, with no significant ICP changes. Arterial oxygen $\left(\mathrm{P}_{\mathrm{a}} \mathrm{O}_{2}\right)$ and carbon dioxide $\left(\mathrm{P}_{\mathrm{a}} \mathrm{CO}_{2}\right)$ tensions remained stable. $\mathrm{AJDO}_{2}$ fell significantly and $\mathrm{P}_{\mathrm{br}_{2}} \mathrm{O}_{2}$ rose significantly. There was a non-significant increase in $\mathrm{P}_{\mathrm{br}} \mathrm{CO}_{2}$ (and a concomitant decrease in $\mathrm{pH}_{\mathrm{br}}$ ). The mean cerebral concentrations of glucose, lactate, pyruvate, and glutamate, and the lactate to pyruvate ratio remained stable.

\section{Cerebral variables and neurochemistry during defervescence}

On average, intracranial temperature fell from $39.2(0.4)$ to $38(0.4){ }^{\circ} \mathrm{C} . \mathrm{P}_{\mathrm{a}} \mathrm{O}_{2}$ and $\mathrm{P}_{\mathrm{a}} \mathrm{CO}_{2}$ did not change. Jugular saturation dropped significantly while the corresponding $\mathrm{AJDO}_{2}$ increase was not significant. $\mathrm{P}_{\mathrm{br}} \mathrm{O}_{2}$ and $\mathrm{P}_{\mathrm{br}} \mathrm{CO}_{2}$ dropped slightly (not significantly) and $\mathrm{pH}_{\mathrm{br}}$ rose $(\mathrm{p}<0.01)$. During the return to normothermia, ICP decreased significantly $(p<0.01)$. Mean cerebral concentrations of the metabolites did not change.

\section{Subcutaneous biochemical data}

Lactate and pyruvate concentrations fell slightly $(\mathrm{p}<0.05)$ during the onset of pyrexia. No significant changes were recorded when temperature returned towards baseline.

\section{DISCUSSION}

Hyperthermia exacerbates ischaemic neuronal damage. Experimental studies have shown that the extent of postischaemic injury is related to the rise in temperature. ${ }^{14}$ In a model of focal cerebral ischaemia, hyperthermia 


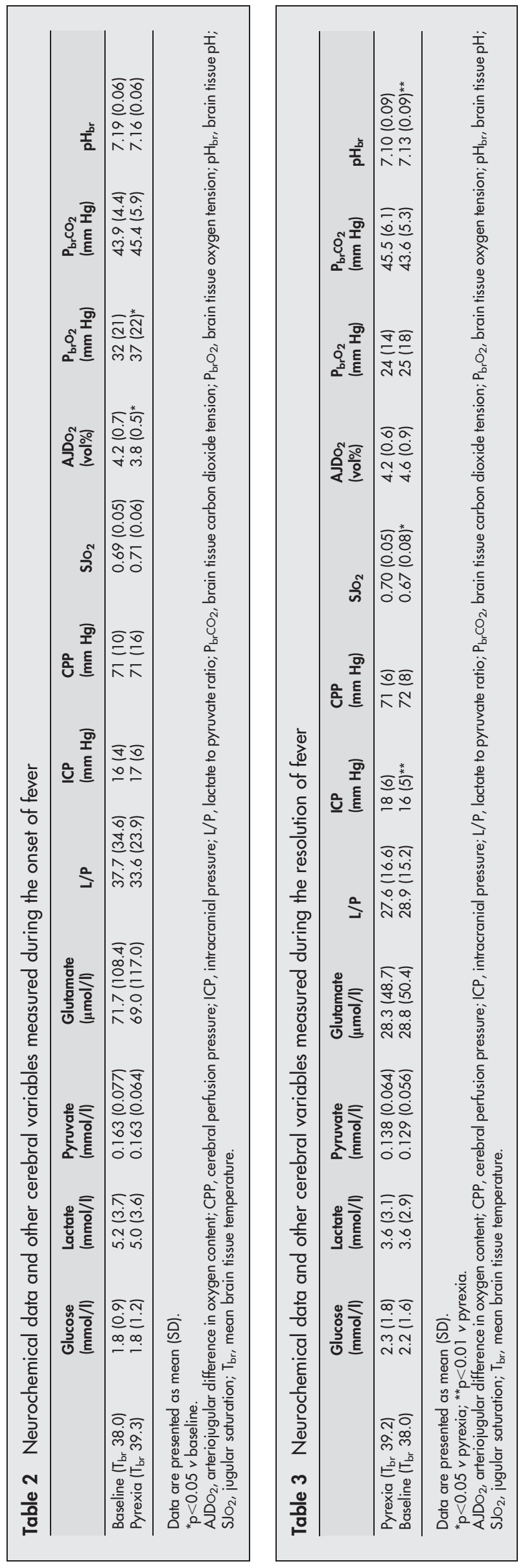

significantly accelerated the transformation of partially damaged tissue to infarction. ${ }^{15}$ The same deleterious effect was confirmed in models of cryogenic ${ }^{16}$ and traumatic ${ }^{17}$ brain injury. In the clinical setting, tympanic membrane temperature was related to initial stroke severity, infarct size, mortality, and outcome in 390 patients admitted to hospital with acute stroke. ${ }^{3}$ Even small increases in body temperature $\left(\geqslant 1^{\circ} \mathrm{C}\right)$ were seen to alter postischaemic neurological outcome in $\operatorname{dogs}^{18}$ and humans. ${ }^{3}$

Fever is a common problem during neurointensive care. Kilpatrick, reviewing 428 patients, detected 946 febrile episodes. Despite the use of antipyretic treatment for $86 \%$ of the febrile episodes, $57 \%$ lasted longer than four hours and $5 \%$ longer than 12 hours. ${ }^{2}$ Stocchetti et al reported that 80 of 110 cases admitted to intensive care because of severe traumatic brain injury suffered pyrexia. ${ }^{19}$ Both physical and pharmacological treatments seemed poorly effective at controlling body temperature. ${ }^{19}$ Fever was the longest lasting secondary insult among 124 head injured patients and its duration was a significant predictor of mortality. ${ }^{1}$ In the present study, hyperthermia was recorded for approximately one third of the total monitoring time.

Direct measurement of brain temperature may help clarify the impact of pyrexia on cerebral tissue. Brain temperature usually exceeds body core temperature, the mean difference being $0.4^{\circ} \mathrm{C}$ at the febrile peak. ${ }^{20}$ The Society of Critical Care Medicine defines fever in the ICU as an oral, rectal, or central (intravascular thermistor) temperature of $38.3^{\circ} \mathrm{C}$ or more. ${ }^{21}$ Thus we considered an intracranial temperature $\geqslant 38.7^{\circ} \mathrm{C}$ as pyrexia, and arbitrarily defined normothermia as a brain temperature around $38^{\circ} \mathrm{C}$.

Microdialysis allows recovery of metabolites from the extracellular space. Cerebral concentrations of lactate and glutamate and the lactate to pyruvate ratio may rise after acute brain damage, reflecting alterations in both glucose metabolism and excitatory amino acids..$^{22-24}$ Brain tissue oxygen tension can be measured continuously using small probes directly implanted in the cerebral cortex. This variable reflects the balance between cerebral oxygen delivery and consumption. Clinical studies have shown $\mathrm{P}_{\mathrm{br}} \mathrm{O}_{2}$ to be closely related to the regional blood flow. ${ }^{25}$ Tissue oxygenation seems to become inadequate whenever $\mathrm{P}_{\mathrm{br}_{2}} \mathrm{O}_{2}$ falls below 20 $\mathrm{mm} \mathrm{Hg}^{26}$; lower values were associated with a bad outcome. ${ }^{27}$

In the present study, neurochemical data at baseline showed increases in lactate and glutamate and in the lactate to pyruvate ratio, ${ }^{13}$ indicating metabolic stress. Despite a considerable rise in brain temperature-to above $39^{\circ} \mathrm{C}$ - only minor intracranial changes were detected. During the onset of fever there were small non-significant increases of ICP and $\mathrm{SJO}_{2}$; correspondingly, $\mathrm{AJDO}_{2}$ dropped significantly. When brain temperature fell back towards baseline, both ICP and $\mathrm{SJO}_{2}$ decreased significantly, whereas $\mathrm{AJDO}_{2}$ showed a tendency towards higher values. We saw no significant neurochemical alterations, such as an increase in the lactate to pyruvate ratio or glutamate concentration, during either effervescence or defervescence. Pyrexia did not cause any substantial biochemical change, even in the subcutaneous tissue. The only significant modifications consisted of a reduction in both lactate and pyruvate during the onset of fever.

Subcutaneous concentrations of metabolites can be considered a rough indicator of plasma levels owing to the lack of barriers between the vascular compartment and the surrounding tissue. ${ }^{28}$ The concentrations of subcutaneous markers, especially lactate, were lower than the corresponding cerebral ones, meaning that extracerebral contamination of the brain findings was unlikely.

Temperature influences neuronal metabolic activity. ${ }^{6}$ As we did not measure cerebral blood flow (CBF), we could not 
directly investigate the cerebral metabolic rate of oxygen $\left(\mathrm{CMRO}_{2}\right)$ or glucose (CMRgluc). However, our data suggest that even when $\mathrm{CMRO}_{2}$ and CMRgluc were expected to rise, possibly causing an uncoupling of flow and metabolism in the injured brain, this did not happen. Cerebral extracellular glucose concentration remained stable, as if the expected rise in consumption was being matched by an increase in delivery. Accordingly, oxygenation remained adequate and the lactate to pyruvate ratio, a reliable indicator of the cellular redox state, did not rise.

Overall, these data indicate that the delivery of glucose and oxygen to the brain changed in line with metabolic demand during the onset of fever. Indicators of both global $\left(\mathrm{SJO}_{2}\right.$ and $\left.\mathrm{AJDO}_{2}\right)$ and local $\left(\mathrm{P}_{\mathrm{br}_{2}}\right)$ cerebral oxygenation remained normal or even improved during effervescence. $\mathrm{AJDO}_{2}$, which is the ratio of oxygen consumption to $\mathrm{CBF}$, would have been expected to increase, as $\mathrm{CMRO}_{2}$ is likely to rise with temperature. Nonetheless, it was reduced at the febrile peak, suggesting an increase in CBF. Major cerebral vasodilatation has been suggested as the cause of a rise in CBF and cerebral volume during fever. ${ }^{20}$ The current study further suggests that $\mathrm{CBF}$ may remain coupled to hyperthermia related hypermetabolism even after acute brain damage. However, the same compensatory mechanism that preserves metabolism may have other major undesirable intracranial effects. Increases in $\mathrm{CBF}$ and volume may trigger intracranial hypertension, especially if intracranial elastance is altered. In our patients ICP rose only slightly, and not significantly, possibly because intracranial compliance was preserved.

The biochemical profile did not change even during the resolution of fever, strengthening the view that compensatory mechanisms were active during pyrexia. Both ICP and $\mathrm{SJO}_{2}$ decreased significantly, possibly as a result of a reduction in $\mathrm{CBF}$.

How can we reconcile these findings with previous reports that hyperthermia is harmful to the injured brain? Two comments are necessary. First, the deleterious role of hyperthermia has been proved during cerebral ischaemia and stroke, but there is much less evidence of temperature related brain damage when CBF can keep up with metabolic requirements. Duration of pyrexia was a significant predictor of mortality in head injured patients, ${ }^{1}$ but it was not clarified whether the mortality reflected the underlying infection or the fever itself. Subsequent studies did not show any relation between fever and outcome after traumatic brain injury. ${ }^{2}{ }^{19}$ During ischaemia, when CBF obviously cannot increase, the greater metabolic demand cannot be satisfied and irreversible changes take place. That may not hold true in other circumstances.

Second, our findings do not prove that pyrexia is safe for the brain. They merely suggest that CBF and oxygenation may remain adequate for metabolic requirements in the setting of non-ischaemic acute brain damage, so that no cerebral biochemical perturbation occurs. But the same mechanism that is protective in neurochemical terms has the deleterious potential of increasing cerebral blood volume and ICP.

Some limitations of this study must be recognised. Our analysis involved only a limited number of patients and was restricted to episodes, in order to make a clear separation between phases at different brain temperature. This meant that only $8 \%$ of the data collected ( 142 hours of a total of 1822 hours' monitoring) were selected and examined. While this selection has the advantage of isolating the net effect of temperature changes, it may well not have captured the overall picture. We did not measure $\mathrm{CBF}$, so our theories on the impact of pyrexia on $\mathrm{CBF}, \mathrm{CMRO}_{2}$, and $\mathrm{CMRgluc}$ are purely speculative. Finally, the wide variability of the neurochemical recordings needs to be discussed further.
The microdialysis technique has some inherent limitationsfor example, the catheter can only monitor a small volume of parenchyma (a few cubic millimetres). Values collected from morphologically homogeneous areas of the brain are presumably representative of average concentrations in the remaining tissue; nonetheless, small differences in catheter positioning could have contributed to some of the variability in the baseline data. Patients in the study had all suffered acute cerebral damage of either traumatic or vascular origin. All were comatose, but the motor component of GCS at the time of enrolment ranged from 1 to 5 . Aware of these limitations, we focused our attention more on neurochemical changes occurring during a febrile episode than on absolute values collected at a given brain temperature.

\section{Conclusions}

In this series of severely ill patients monitored after acute brain damage, cerebral oxygenation was preserved and no signs of anaerobic metabolism were detected during the onset of fever, possibly because of a concurrent increase in cerebral blood flow. Hyperthermia remains a frequent and serious problem in brain injured patients during intensive care. However, it seems to be well tolerated when cerebral ischaemia is not the main pathophysiological mechanism and when it does not cause intracranial hypertension.

\section{Authors' affiliations}

N Stocchetti, A Protti, M Lattuada, S Magnoni, L Longhi, L Ghisoni, E R Zanier, Milan University, Neuroscience Intensive Care, Ospedale Policlinico IRCCS, Milan, Italy

M Egidi, Neurosurgery Division, Ospedale Policlinico IRCCS

Competing interests: NS has been reimbursed by CMA-Microdialysis for attending a consensus conference meeting.

\section{REFERENCES}

1 Jones PA, Andrews PJ, Midgley S, et al. Measuring the burden of secondary insults in head-injured patients during intensive care. J Neurosurg Anesthesiol 1994;6:4-14.

2 Kilpatrick MM, Lowry DW, Firlik AD, et al. Hyperthermia in the neurosurgical intensive care unit. Neurosurgery 2000;47:850-5.

3 Reith J, Jorgensen HS, Pedersen PM, et al. Body temperature in acute stroke: relation to stroke severity, infarct size, mortality, and outcome. Lancet 1996;347:422-5

4 Ginsberg MD, Busto R. Combating hyperthermia in acute stroke. A significant clinical concern. Stroke 1998;29:529-34

5 Busija DW, Leffler CW, Pourcyrous M. Hyperthermia increases cerebral metabolic rate and blood flow in neonatal pigs. Am J Physiol 1988;255:H343-6.

6 Mickley GA, Cobb BL, Farrell ST. Brain hyperthermia alters local cerebral glucose utilization: a comparison of hyperthermic agents. Int J Hyperthermia 1997:13:99-114.

7 Benveniste $\mathbf{H}$, Huttemeier PC. Microdialysis - theory and application. Prog Neurobiol 1990;35:195-215.

8 Dings J, Meixensberger J, Jager A, et al. Clinical experience with 118 brain tissue oxygen partial pressure catheter probes. Neurosurgery 1998:43: 1082-95

9 Hoffman WE, Charbel FT, Portillo GG, et al. Regional tissue $\mathrm{pO}_{2}$, $\mathrm{pCO}_{2}, \mathrm{pH}$ and temperature measurement. Neurol Res 1998;20(suppl 1):S81-4.

10 Bacher A, Kwon JY, Zornow MH. Effects of temperature on cerebral tissue oxygen tension, carbon dioxide tension, and $\mathrm{pH}$ during transient global ischemia in rabbits. Anesthesiology 1998;88:403-9.

11 Soukup J, Zauner A, Doppenberg EM, et al. Relationship between brain temperature, brain chemistry and oxygen delivery after severe human head injury: the effect of mild hypothermia. Neurol Res 2002;24:161-8.

12 Busto R, Globus MY, Dietrich WD, et al. Effect of mild hypothermia on ischemia-induced release of neurotransmitters and free fatty acids in rat brain. Stroke 1989;20:904-10.

13 Reinstrup P, Stahl N, Mellergard P, et al. Intracerebral microdialysis in clinical practice: baseline values for chemical markers during wakefulness, anesthesia, and neurosurgery. Neurosurgery 2000;47:701-9.

14 Busto R, Dietrich WD, Globus MY, et al. Small differences in intra-ischemic brain temperature critically determine the extent of ischemic neuronal injury. J Cereb Blood Flow Metab 1987:7:729-38.

15 Reglodi D, Somogyvari-Vigh A, Maderdrut JL, et al. Post-ischemic spontaneous hyperthermia and its effects in middle cerebral artery occlusion in the rat. Exp Neurol 2000;163:399-407. 
16 Clasen RA, Pandolfi S, Laing I, et al. Experimental study of relation of fever to cerebral edema. J Neurosurg 1974;41:576-81.

17 Dietrich WD, Alonso O, Halley $M$, et al. Delayed post-traumatic brain hyperthermia worsens outcome after fluid percussion brain injury: a light and electron microscopic study in rats. Neurosurgery 1996;38:533-41.

18 Wass CT, Lanier WL, Hofer RE, et al. Temperature changes of $>$ or $=1$ degree $C$ alter functional neurologic outcome and histopathology in a canine model of complete cerebral ischemia. Anesthesiology 1995;83:325-35.

19 Stocchetti N, Rossi S, Zanier ER, et al. Pyrexia in head-injured patients admitted to intensive care. Intensive Care Med 2002;28:1555-62.

20 Rossi S, Zanier ER, Mauri I, et al. Brain temperature, body core temperature, and intracranial pressure in acute cerebral damage. J Neurol Neurosurg Psychiatry 2001;71:448-54.

21 O'Grady NP, Barie PS, Bartlett J, et al. Practice parameters for evaluating new fever in critically ill adult patients. Task Force of the American College of Critical Care Medicine of the Society of Critical Care Medicine in collaboration with the Infectious Disease Society of America. Crit Care Med 1998;26:392-408.

22 Enblad P. Valtysson J, Andersson J, et al. Simultaneous intracerebral microdialysis and positron emission tomography in the detection of ischemia in patients with subarachnoid hemorrhage. J Cereb Blood Flow Metab 1996; 16:637-44.

23 Bullock R, Zauner A, Woodward JJ, et al. Factors affecting excitatory amino acid release following severe human head injury. J Neurosurg 1998:89:507-18.

24 Goodman JC, Valadka AB, Gopinath SP, et al. Extracellular lactate and glucose alterations in the brain after head injury measured by microdialysis. Crit Care Med 1999;27:1965-73.

25 Doppenberg EM, Zauner A, Bullock R, et al. Correlations between brain tissue oxygen tension, carbon dioxide tension, $\mathrm{pH}$, and cerebral blood flow - $\mathrm{c}$ better way of monitoring the severely injured brain? Surg Neurol 1998;49:650-4.

26 Doppenberg EM, Zauner A, Watson JC, et al. Determination of the ischemic threshold for brain oxygen tension. Acta Neurochir Suppl (Wien) 1998:71:166-9.

27 Valadka AB, Gopinath SP, Contant CF, et al. Relationship of brain tissue $\mathrm{PO}_{2}$ to outcome after severe head injury. Crit Care Med 1998;26:1576-81.

28 Hutchinson PJ, O'Connell MT, Maskell LB, et al. Monitoring by subcutaneous microdialysis in neurosurgical intensive care. Acta Neurochir Suppl (Wien) 1999:75:57-9. 